\title{
Awareness of the Signs, Symptoms, and Risk Factors of Cancer and the Barriers to Seeking Help in the UK: Comparison of Survey Data Collected Online and Face-to-Face
}

\author{
Katie Connor, MMath; Briony Hudson, PhD; Emily Power, PhD \\ Cancer Research UK, London, United Kingdom
}

\section{Corresponding Author:}

Briony Hudson, $\mathrm{PhD}$

Cancer Research UK

Angel Building

407 St John Street

London, EC1V 4AD

United Kingdom

Phone: 4402034695376

Fax: 4402034695376

Email: briony.hudson@ cancer.org.uk

\section{Abstract}

Background: Cancer is the second leading cause of death globally, causing an estimated 9.6 million deaths in 2018. Low cancer symptom awareness has been associated with poor cancer survival for all cancers combined. The Cancer Awareness Measure (CAM) is a validated, face-to-face survey used since 2008 to measure the UK public's awareness of the symptoms and risk factors of cancer as well as the barriers to seeking help.

Objective: The aim of this study is to explore whether online data collection can produce a representative sample of the UK population, compare awareness of cancer signs and risk factors and the barriers to seeking help between data collected online and face-to-face, and examine the relationships between awareness and demographic variables.

Methods: Differences in awareness of cancer signs, symptoms, and risk factors among samples were explored while adjusting for demographic differences (age, gender, ethnicity, educational level, marital status, and country of residence) to distinguish the effect of data collection method. Multivariate logistic regression models were used to calculate adjusted odds ratios for recall and recognition of signs and symptoms, risk factors, and barriers to seeking help.

Results: A total of 4075 participants completed the CAM, 20\% ( $n=819)$ via face-to-face interviews and 80\% online ( $\mathrm{n}=3256$; agency A: $n=1190$; agency B: $n=2066$ ). Comparisons of data collected using face-to-face interviews and online surveys revealed minor differences between samples. Both methods provided representative samples of the UK population with slight differences in awareness of signs, symptoms, and risk factors and frequency of help-seeking barriers reported.

Conclusions: These findings support a move to online data collection for the CAM. The flexibility afforded will enable the CAM to explore a wider range of issues related to the prevention, early diagnosis, and treatment of cancer.

(JMIR Cancer 2020;6(1):e14539) doi: $\underline{10.2196 / 14539}$

\section{KEYWORDS}

neoplasms; surveys and questionnaires; cross-sectional study; awareness; help-seeking behavior; cancer

\section{Introduction}

\section{Background}

Cancer is the second leading cause of death globally, causing an estimated 9.6 million deaths in 2018 [1]. Half of the people diagnosed with cancer in England and Wales survive for 10 years or more, but approximately 4 in 10 cases of cancer in the
UK could be prevented [2]. Cancer survival has consistently been reported to be lower in the UK than similar European countries $[3,4]$.

Late-stage diagnosis contributes to excess deaths for bowel [5], breast [6], and lung cancer [7] in the UK. Late diagnosis could be related to low awareness of symptoms, leading to delays in seeking medical help. Low cancer symptom awareness has been 
associated with delays in seeking medical help and poor cancer survival for all cancers combined [8].

Earlier detection can improve patient experience [9], costs to the National Health Service (NHS) [10], and cancer survival, but it relies partly on prompt presentation [11]. Understanding and potentially improving awareness of cancer signs is an important step in reducing the incidence of late-stage cancer and reducing cancer deaths in the UK.

In 2008, Cancer Research UK, in partnership with University College London, King's College London, and University of Oxford, developed the Cancer Awareness Measure (CAM) [12]. The CAM is a validated survey designed to measure awareness of signs, symptoms, and risk factors for cancer and potential barriers to seeing a doctor.

Cancer Research UK has used the CAM to collect data biannually from 2008 to 2014 from a representative sample of the UK population via the Office for National Statistics (ONS) Opinions and Lifestyle Survey. Questions in the survey are a combination of recall and recognition questions, designed to assess public awareness. Recall questions are open-ended questions, asking participants to list as many cancer warning signs and risk factors that they can think of. These are followed by recognition questions, where participants are given a list of warning signs and risk factors and asked yes/no do they think these are risk factors or warning signs of cancer.

Data from the CAM indicate that the average number of cancer warning signs recognized by representative samples of the UK population has increased from 6.4 (SD 1.9) in 2008 to 6.8 (SD $1.5)$ in 2014 out of a possible nine warning signs posed in the survey [13]. Recall of risk factors appears to have followed the opposite pattern, with recall decreasing from a mean 2.2 in 2008 to 2.0 in 2014 [13]. Awareness of cancer signs and risk factors has consistently been found to be lower among men [14,15], younger adults [14], and those from lower socioeconomic groups $[14,16,17]$ or ethnic minorities $[15,18]$.

Although CAM data have traditionally been collected via face-to-face interviews conducted by the ONS, the response rates have declined over the years (from $61 \%$ in 2008 to $47 \%$ in 2017). This study explores the viability of moving data collection online, a move seen in many large market research organizations. In Great Britain, $90 \%$ of households have access to the internet, and $73 \%$ of people have accessed the internet with a mobile phone [19]. The benefits of online data collection include lower costs [17], higher data quality [20], and a faster rate of return and lower data entry times [21]. Conversely, the limitations may include sampling issues [21] and differences in sampling methodologies [22].

Although the relationships among questionnaire modality, response rates, and accuracy have been described as complex [23], previous research exploring the impact of data collection method is encouraging. Socially desirable behaviors have been reported to be less likely to be disclosed in interviews than online questionnaires [24], and disease prevalence rates are much closer to known rates when using internet studies compared with data collected over the telephone or face-to-face [25].

\section{Research Objectives}

The primary aim of this study is to identify the extent to which public awareness of cancer and attitudes toward seeking help vary by data collection method (face-to-face vs online data) in adults (aged $\geq 18$ years) in Great Britain. The research objectives are to (1) explore whether online data collection can produce a representative sample of the UK population (differences between samples); (2) compare the awareness of signs, symptoms, and risk factors for cancer, as well as the barriers to seeking help between data collected online and face-to-face (differences in levels of awareness); and (3) explore whether any relationships observed between awareness and demographic variables are consistent across samples (interactions between survey provider and demographic variables).

\section{Methods}

\section{Participants and Recruitment}

\section{Face-to-Face Sample}

Between January and March 2017, face-to-face data were collected by the ONS via the Opinions and Lifestyle survey. The ONS use stratified probability sampling to select sampling points from a database of 27 million private households in the UK. A random sample of addresses from each sampling point were selected, and interviewers invited one adult respondent from each household to complete the CAM using a face-to-face, computer-assisted interview.

\section{Online Samples}

Online samples were recruited by two market research agencies. Agency A recruited participants to their online panel via a face-to-face survey. Agency A used a probability-based approach for recruitment, which avoids in-built bias commonly found in online panel sampling methods. Agency B used "active sampling," in which a subsample of participants were selected from their more than 800,000-member panel based on their age, gender, social class, and education. Agency B panel members are recruited from standard advertising and strategic partnerships with a range of websites.

\section{Great Britain Population Data}

The Great Britain population statistics were taken from the ONS (midyear population estimates, Households and Individuals Internet Access survey), census data, and NHS Digital (Health Survey for England).

\section{Outcome Measures}

Variables collected in the CAM are outlined in Textbox 1. Details of the development and content of the CAM can be found elsewhere [12].

To reduce bias, open-ended questions about signs, symptoms, and risk factors were asked before closed questions. The number of warning signs endorsed or risk factors recognized were summed to produce total scores. Coding manuals were provided to all market research agencies regarding how to code recalled items to ensure consistency. 
Textbox 1. Outcome measures.

\section{Sociodemographic characteristics}

- We amended the standard ONS demographic questions and adapted these for online samples where necessary: age, gender, educational attainment, ethnicity, country of residence marital status, internet use, and self-reported health status.

Awareness of signs and symptoms of cancer (recall and recognition)

- Recall: "There are many warning signs and symptoms of cancer, please name as many as you can think of."

- Recognition: "Could any of the following be signs of cancer?": lump or swelling, persistent unexplained pain, unexplained bleeding, persistent cough or hoarseness, persistent change in bowel or bladder habits, difficulty swallowing, change in the appearance of a mole, a sore that does not heal, and unexplained weight loss.

\section{Awareness of cancer risk factors (recall and recognition)}

- Recall: "What things do you think affect a person's chance of developing cancer?"

- Recognition: "Could any of the following increase a person's chance of developing cancer?": smoking, getting sunburned, exposure to another person's smoking, drinking alcohol, having a close relative with cancer, being overweight, being older, not eating many fruits and vegetables, not eating enough fiber, eating too much red or processed meat, not doing much physical activity, and infection with HPV (human papillomavirus).

Barriers to seeing a general practitioner

- "Which of the following might put you off going to the doctor?"

- Participants were asked to indicate whether any of a range of barriers might put them off seeing a doctor on a 5-point agreement scale from strongly agree to strongly disagree.

\section{Statistical Analysis}

\section{Weighting and Sample Differences}

Each market research agency provided their own weighting variable to ensure the sample was representative of the Great Britain population and to adjust for nonresponse where possible. Our analyses were carried out using the weighted variable provided by each agency. We did not create a bespoke weighting variable because of the lack of nonresponse data available. See Multimedia Appendix 1 for how each survey provider weighted their data.

Weighted sample demographics were compared between the surveys to explore any differences between the collected samples. Differences between survey responses and Great Britain population statistics were not tested for significance because confidence intervals for Great Britain data were not available.

\section{Differences in Levels of Awareness}

Differences in awareness of cancer signs and symptoms and risk factors between samples were explored while adjusting for demographic differences (age, gender, ethnicity, educational level, marital status, and country of residence) with the aim of determining the effect of data collection method.

Multivariate logistic regression models were used to calculate adjusted odds ratios for recall and recognition of signs and symptoms, risk factors, barriers to seeking help, and awareness of bowel screening. The outcome variable was binary to show if the responder did or did not recall or recognize signs and symptoms, risk factors, barriers to seeking help, and awareness of bowel screening. Only statistically significant variables were included in the final logistic regression models.

\section{Interactions Between Outcomes and Demographic Variables}

Interaction terms between survey provider and key demographics (gender, age, education level, marital status, ethnicity, country, long-term health, and internet usage) were added to the awareness models. Whether data collected by different methods varied by demographic variables, while controlling for any differences in sample characteristics between the surveys, was explored.

\section{Results}

\section{Participants}

In total, 4075 participants completed the CAM. Online participants made up $80 \%(n=3256)$ of the sample (agency A: $n=1190$; agency $B: n=2066)$. The remaining $20 \%(n=819)$ of participants completed face-to-face interviews.

\section{Differences Between Samples}

The three weighted samples were generally representative of the Great Britain population (Table 1). 
Table 1. Demographic characteristics by survey provider and compared with Great British population statistics (N=4075).

\begin{tabular}{|c|c|c|c|c|}
\hline \multirow[t]{2}{*}{ Demographic } & \multirow{2}{*}{$\begin{array}{l}\text { Face-to-face, } \% \\
\text { Office for National Statistics }(n=819)\end{array}$} & \multicolumn{2}{|l|}{ Online, $\%^{\mathrm{a}}$} & \multirow[t]{2}{*}{ Great Britain population, $\%$} \\
\hline & & Agency A (n=1190) & Agency B (n=2066) & \\
\hline \multicolumn{5}{|l|}{ Age groups } \\
\hline $18-24$ & 10.2 & 8.4 & 12.0 & $15.1^{\mathrm{b}}$ \\
\hline $25-44$ & 33.8 & 33.4 & 32.1 & 32.1 \\
\hline $45-54$ & 18.0 & 17.9 & 20.9 & 17.2 \\
\hline $55-64$ & 15.1 & 16.9 & 16.9 & 13.9 \\
\hline$\geq 65$ & 22.8 & 23.1 & 18.1 & 21.7 \\
\hline Missing & - & 0.2 & - & - \\
\hline \multicolumn{5}{|l|}{ Gender } \\
\hline Male & 49.1 & 49.9 & 48.0 & 49.3 \\
\hline Female & 50.9 & 50.1 & 52.0 & 50.7 \\
\hline \multicolumn{5}{|l|}{ Ethnicity } \\
\hline White & 87.9 & 87.5 & 92.7 & 86.0 \\
\hline Nonwhite & 12.1 & 12.5 & 7.3 & 14.0 \\
\hline \multicolumn{5}{|l|}{ Country of residence } \\
\hline England & 86.6 & 84.7 & 86.3 & 86.5 \\
\hline Scotland & 8.3 & 10.2 & 8.7 & 8.6 \\
\hline Wales & 5.1 & 5.1 & 5.0 & 4.9 \\
\hline \multicolumn{5}{|c|}{ Higher education qualification } \\
\hline Degree & 30.5 & 26.4 & 32.2 & 27.1 \\
\hline Below degree & 42.7 & 55.7 & 54.1 & 44.7 \\
\hline No qualifications & 12.7 & 15.5 & 6.6 & 23.0 \\
\hline Other & 14.1 & 2.3 & 5.5 & 5.2 \\
\hline Don’t know & - & - & 1.6 & - \\
\hline \multicolumn{5}{|l|}{ Marital status } \\
\hline Partner & 50.5 & 62.6 & 61.7 & 50.9 \\
\hline No partner & 49.5 & 37.4 & 38.3 & 49.1 \\
\hline \multicolumn{5}{|l|}{ Long-term illness } \\
\hline Very good & 37.0 & 20.1 & 15.6 & Very good/good: 76 \\
\hline Good & 42.0 & 48.5 & 47.4 & - \\
\hline Fair & 15.9 & 23.7 & 28.3 & - \\
\hline $\mathrm{Bad}$ & 3.6 & 6.4 & 7.1 & Very bad/bad: 7 \\
\hline Very bad & 1.3 & 1.3 & 1.6 & - \\
\hline Refused & 0.3 & 0.1 & - & - \\
\hline \multicolumn{5}{|l|}{ Internet usage } \\
\hline Several times a day & 64.2 & 65.6 & 79.9 & At least once a day: 80 \\
\hline Once a day & 14.3 & 13.2 & 13.7 & - \\
\hline 4-6 days a week & 3.1 & 2.9 & 3.0 & - \\
\hline 2-3 days a week & 3.7 & 4.2 & 1.6 & - \\
\hline Once a week & 2.1 & 2.4 & 0.6 & At least weekly: 8 \\
\hline Less than once a week & 1.3 & 2.2 & 0.4 & Less than weekly: 2 \\
\hline
\end{tabular}




\begin{tabular}{lllll}
\hline Demographic & $\begin{array}{l}\text { Face-to-face, } \% \\
\text { Office for National Statistics }(\mathrm{n}=819)\end{array}$ & $\begin{array}{l}\text { Online, } \%^{\mathrm{a}} \\
\text { Agency A }(\mathrm{n}=1190)\end{array}$ & $\begin{array}{l}\text { Great Britain population, } \% \\
\text { Agency B (n=2066) }\end{array}$ \\
\hline Never & 9.2 & 9.5 & 0.8 & $\begin{array}{l}\text { Did not use in the last } 3 \\
\text { months: } 10\end{array}$ \\
Don't know & 0.9 & - & - & - \\
Refused & 1.3 & - & - & - \\
\hline
\end{tabular}

${ }^{\text {a }}$ Percentages are weighted using the weighting variable provided by each survey agency; see Multimedia Appendix 1 for more information.

${ }^{\mathrm{b}}$ Ages 15-24 years.

The gender split of all three samples largely matched the Great Britain population; however, both online samples were older than the ONS sample and the Great Britain population. Scottish participants were slightly overrepresented by agency A $(10.2 \%$ vs $8.6 \%$ of Great Britain population).

All samples included a higher proportion of white participants than the Great Britain population (Great Britain population: $86 \%$; agency A: $87.5 \%$; agency $\mathrm{B}, 93 \%$ ) and reported higher educational attainment. Both online samples had a larger proportion of participants with a partner (agency A: 63\%; agency B: $62 \%$ ) compared with the Great Britain population (50.9\%) and were more likely to report being in good health (agency A: 48.5\%; agency B: $47.4 \%$; ONS: $42 \%$ ). Face-to-face participants were less likely to report their health as bad (3.6\%; agency A: 6.4\%; agency B: $7.1 \%$; Great Britain population: $7 \%$ ). More than $90 \%$ of agency B participants reported using the internet more than once a day compared with $78.5 \%$ of face-to-face and $78.8 \%$ of agency A participants.

\section{Differences in Levels of Awareness (Outcomes)}

The number of cancer warning signs and risk factors recognized and recalled within each sample are included in Multimedia Appendix 2.

\section{Cancer Warning Signs \\ Recall of Warning Signs}

Agency A participants recalled significantly more signs of cancer than other participants, with a mean recall of five signs of cancer compared with three for both face-to-face and agency B participants. Figure 1 shows the percentage of participants recalling cancer warning signs.

A lump was the most frequently recalled sign in all three samples (agency A: $75.1 \%$, agency B: $64.2 \%$, face-to-face: $58.6 \%$; Figure 1). Compared with face-to-face participants, agency B participants were less likely to recall bleeding or blood loss (29\% vs $35 \%, P<.001$, OR 0.7, $95 \%$ CI 0.6-0.8) and sores ( $1.5 \%$ vs $2.7 \%, P=.003$, OR $0.4,95 \%$ CI $0.2-0.8)$. Agency A participants were more likely than face-to-face participants to recall a lump (75\% vs $59 \%, P<.001$, OR $2.3,95 \%$ CI $1.8-2.8)$, pain $(48 \%$ vs $34 \%, P<.001$, OR 1.9, 95\% CI 1.6-2.3), bleeding or blood loss (46\% vs $35 \%, P<.001$, OR $1.5,95 \%$ CI $1.3-1.8)$, and blood in urine $(18 \%$ vs $8 \%, P<.001$, OR $2.5,95 \%$ CI 1.9-3.3). Participants from both online samples were more likely than face-to-face participants to recall change in bowel or bladder habits (agency A: 46\%, $P<.001$, OR 2.9, 95\% CI 2.4-3.5; agency B: $34 \%, P<.001$, OR 1.5, 95\% CI 1.2-1.8 vs face-to-face: $27 \%$ ), blood in feces (agency A: 26\%, $P<.001$, OR 4.2, 95\% CI 3.3-5.6; agency B: $17 \%, P<.001$, OR 2.1, 95\% CI 1.6-2.7 vs face-to-face: $9.6 \%$ ) and tiredness (agency A: $28 \%, P<.001$, OR 2.1, 95\% CI 1.7-2.7; agency B: $22 \%, P=.04$, OR $1.3,95 \%$ CI $1.0-1.6$ vs face-to-face: $16 \%)$. Online samples were more likely to answer "don't know" when asked to recall warning signs for cancer than face-to-face responders (agency A: $1.8 \%, P=.02$, OR 4.4, 95\% CI 1.5-19.3; agency B: $6.1 \%, P<.001$, OR 20.4, 95\% CI 7.5-38.5; face-to-face: $0.2 \%$ ). 
Figure 1. Percentage of participants recalling cancer warning signs.

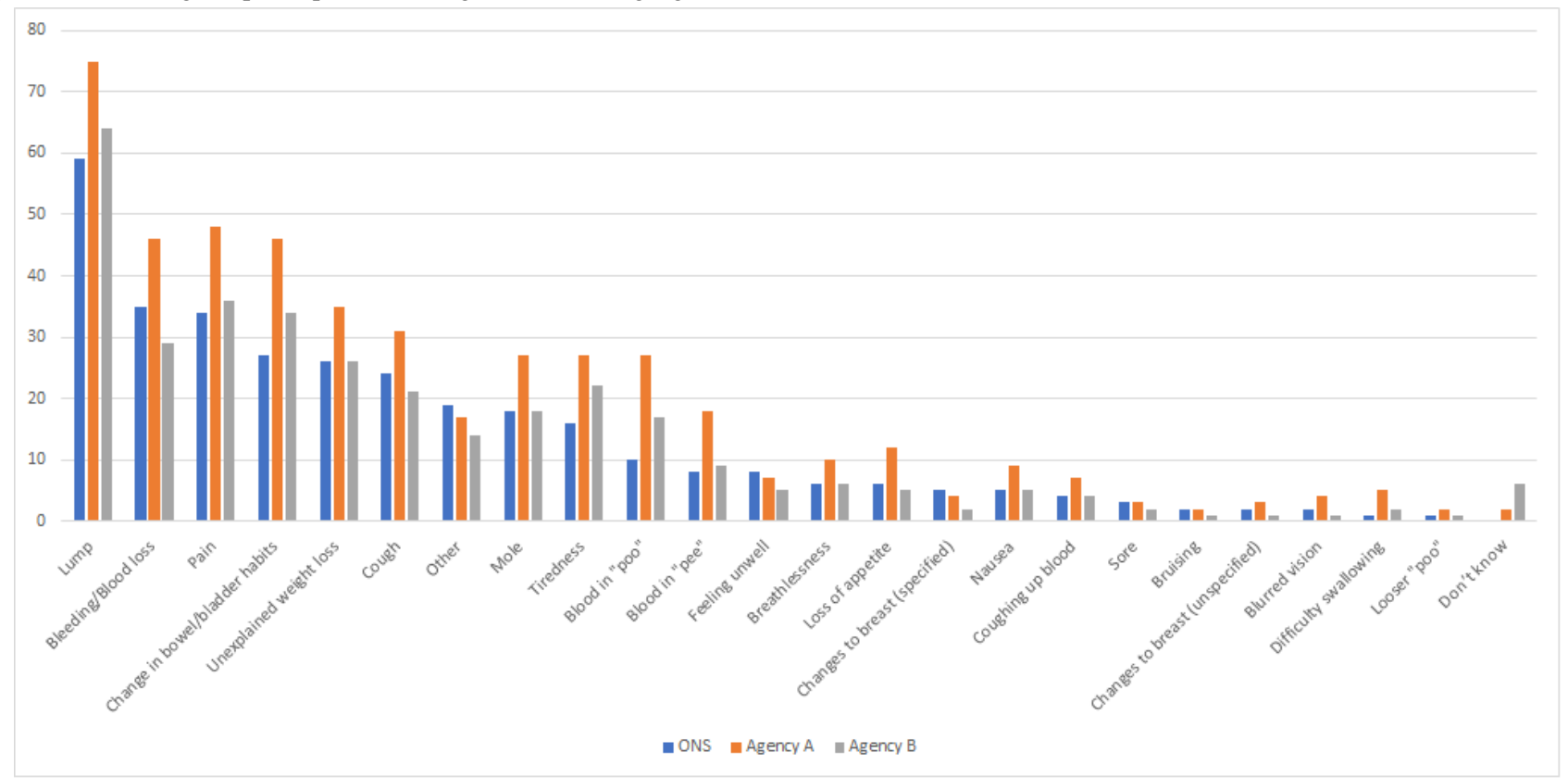

\section{Recognition of Cancer Signs}

Agency A participants demonstrated greater recognition of signs and symptoms, recognizing a mean of eight of nine presented signs and symptoms of cancer, compared with ONS and agency B participants who recognized a mean of seven.

An unexplained lump or swelling was the most commonly recognized sign in all samples (face-to-face: $94.7 \%$; agency A: 98.4\%; agency B: 94.7\%; Table 2). Agency A participants were more likely than face-to-face participants to recognize a lump (98\% vs 95\%, $P=.009$, OR 2.4, 95\% CI 1.3-4.6) and unexplained weight loss (96\% vs $89 \%, P<.001$, OR $3.5,95 \%$ CI $2.3-5.5)$.
For other signs, there were no significant differences between agency A and face-to-face responses.

Agency B participants were less likely than face-to-face participants to recognize a lump ( $94 \%$ vs $95 \%, P=.002$, OR 0.4 , $95 \%$ CI $0.3-0.7)$, changes in bowel habits $(88 \%$ vs $90 \%, P<.001$, OR $0.5,95 \%$ CI $0.4-0.7)$, persistent cough $(83 \%$ vs $84 \%, P=.01$, OR $0.7,95 \%$ CI 0.6-0.9), unexplained weight loss ( $87 \%$ vs $89 \%$, $P=.03$, OR $0.7,95 \%$ CI $0.5-0.9)$, persistent difficulty swallowing (76\% vs $78 \%, P=.004$, OR $0.7,95 \%$ CI $0.6-0.9$ ), and unexplained bleeding ( $86 \%$ vs $88 \%, P=.005$, OR $0.7,95 \%$ CI 0.4-0.9). Agency B participants were more likely to recognize a sore that does not heal as a sign or symptom of cancer $(70 \%$ vs $63 \%, P=.01$, OR $1.3,95 \%$ CI $1.1-1.5)$.

Table 2. Percentage of participants from each sample who answered "yes" to the question "Do you think that the following could be a warning sign for cancer?" (N=4075).

\begin{tabular}{|c|c|c|c|c|c|}
\hline \multirow[t]{3}{*}{ Yes, it could } & \multirow{3}{*}{$\begin{array}{l}\text { Face-to-face, } \% \\
\text { Office for National } \\
\text { Statistics }(n=819)\end{array}$} & \multicolumn{4}{|l|}{ Online } \\
\hline & & \multicolumn{2}{|l|}{ Agency A (n=1190) } & \multicolumn{2}{|c|}{ Agency B (n=2066) } \\
\hline & & Participants, $\%$ & $P$ value & Participants, $\%$ & $P$ value \\
\hline Unexplained lump or swelling & 94.7 & 98.4 & .009 & 94.7 & .002 \\
\hline Change in appearance of a mole & 92.9 & 95.9 & .09 & 93.9 & .006 \\
\hline Persistent change in bowel or bladder habits & 89.8 & 91.4 & .58 & 88.2 & .001 \\
\hline Unexplained weight loss & 89.1 & 96.4 & $<.001$ & 86.5 & .03 \\
\hline Unexplained bleeding & 88.0 & 89.1 & .93 & 86.3 & .005 \\
\hline Persistent cough or hoarseness & 83.7 & 86.7 & .10 & 82.8 & .01 \\
\hline Persistent unexplained pain & 79.0 & 82.0 & .05 & 83.8 & .47 \\
\hline Persistent difficulty swallowing & 78.3 & 76.3 & .15 & 76.2 & .004 \\
\hline Sore that does not heal & 63.0 & 66.6 & .18 & 70.0 & .01 \\
\hline
\end{tabular}




\section{Awareness of Risk Factors for Cancer}

\section{Recall of Cancer Risk Factors}

Agency A participants recalled a mean of five risk factors compared with both face-to-face and agency B participants who recalled a mean of three. Fewer agency A participants recalled zero risk factors $(3.2 \%)$ than face-to-face $(8.2 \%)$ or agency B (11.6\%) participants (Multimedia Appendix 1).
The most frequently recalled risk factor within all samples was smoking, but recall was significantly lower in the agency B sample ( $P<.001$, OR $0.4,95 \%$ CI $0.3-0.5$; Table 3$)$. The same pattern was seen for alcohol (agency A: 55\%, $P=.07$, OR 1.2, 95\% CI 1.0-1.4; face-to-face: $54 \%$; agency B: $43 \%, P<.001$, OR $0.7,95 \%$ CI 0.6-0.8). A higher proportion of agency B participants answered "don't know" to this recall question (5.4\%, $P<.001$; face-to-face: $0.1 \%$; agency A: $0.9 \%)$.

Table 3. Recall of risk factors for cancer from the three samples $(\mathrm{N}=4075)$.

\begin{tabular}{|c|c|c|c|c|c|}
\hline \multirow[t]{3}{*}{ Risk factor } & \multirow{3}{*}{$\begin{array}{l}\text { Face-to-face, } \% \\
\text { Office for National } \\
\text { Statistics }(n=819)\end{array}$} & \multicolumn{4}{|l|}{ Online } \\
\hline & & \multicolumn{2}{|l|}{ Agency A (n=1190) } & \multicolumn{2}{|c|}{ Agency B (n=2066) } \\
\hline & & Participants, $\%$ & $P$ value & Participants, $\%$ & $P$ value \\
\hline Smoking & 81.9 & 81.5 & .96 & 68.6 & .001 \\
\hline Alcohol & 53.5 & 55.1 & .07 & 43.3 & .001 \\
\hline Diet (unspecified) & 36.2 & 50.3 & .001 & 40.0 & .02 \\
\hline Sunburn & 25.0 & 30.1 & .001 & 21.1 & .06 \\
\hline Being overweight & 14.9 & 20.0 & .04 & 25.6 & .001 \\
\hline Exercise & 13.8 & 24.1 & .001 & 16.4 & .06 \\
\hline Occupational exposure & 13.7 & 12.2 & .88 & 8.5 & .001 \\
\hline Genes & 11.5 & 23.8 & .001 & 19.8 & .001 \\
\hline Pollution & 10.4 & 13.0 & .002 & 7.8 & .02 \\
\hline Family history & 10.0 & 22.6 & .001 & 15.2 & .003 \\
\hline Lifestyle & 9.6 & 18.1 & .001 & 14.9 & .02 \\
\hline Stress & 8.4 & 11.7 & .001 & 5.6 & .02 \\
\hline Radiation & 5.9 & 6.3 & .19 & 4.7 & .06 \\
\hline High-fat diet & 4.6 & 2.1 & .001 & 1.0 & .001 \\
\hline Red meat & 3.7 & 3.9 & .51 & 3.3 & .80 \\
\hline Sun beds & 3.7 & 5.3 & .09 & 2.0 & .01 \\
\hline Passive smoking & 2.7 & 3.1 & .07 & 1.5 & .001 \\
\hline Older age & 2.3 & 6.1 & .001 & 4.8 & .009 \\
\hline Mobile phones & 1.1 & 0.3 & .60 & 0.2 & .06 \\
\hline Many sexual partners & 1.0 & 0.6 & .98 & 1.5 & .10 \\
\hline Other & 12.9 & 24.5 & .001 & 12.9 & .61 \\
\hline Nothing & 2.8 & 0.0 & - & 0.4 & - \\
\hline Refused & 4.4 & 0.0 & - & 0.0 & - \\
\hline Don't know & 0.1 & 0.9 & .05 & 5.4 & .001 \\
\hline
\end{tabular}

Recall of sunburn $(30 \%, P<.001$, OR 1.7, 95\% CI 1.3-2.0), being overweight (agency A: 20\%, P=.04, OR 1.4, 95\% CI genes $(24 \%, P<.001$, OR 2.4, 95\% CI 1.8-3.0), and lack of exercise (24\%, $P<.001$, OR $2.1,95 \%$ CI 1.6-2.7) as risk factors was significantly higher in the agency A survey compared with the face-to-face survey (sunburn: 25\%; genes: 12\%; lack of exercise: 14\%). Agency B participants were less likely than face-to-face participants to recall occupational exposure $(9 \%$ vs $14 \%, P<.001$, OR $0.6,95 \%$ CI $0.5-0.8$ ), stress (6\% vs $8 \%$, $P=.02$, OR $0.6,95 \%$ CI $0.5-0.9$ ), and high-fat diet (1\% vs $5 \%$, $P<.001$, OR 0.2, 95\% CI 0.1-0.3). Participants from both online surveys were more likely than face-to-face participants to recall 1.1-1.8; agency B: $25 \%, P<.001$, OR 1.8, 95\% CI 1.4-2.2; face-to-face: $15 \%$ ), family history (agency A: $23 \%, P<.001$, OR 2.8, 95\% CI 2.1-3.6; agency B: $15 \%, P=.003$, OR $1.5,95 \%$ CI 1.1-2.0; face-to-face: 10\%), lifestyle (agency A: $18 \%$, $P<.001$, OR $1.8,95 \%$ CI $1.4-2.4$; agency B: $15 \%, P=.02$, OR 1.4, 95\% CI 1.1-1.8; face-to-face: $10 \%$ ), diet (agency A: $50 \%$, $P<.001$ OR 2.2, 95\% CI 1.8-2.7; agency B: 40\%, $P=.02$, OR $1.2,95 \%$ CI 1.0-1.4; face-to-face: $36 \%$ ), and older age (agency A: $6 \%, P<.001$, OR 3.4, 95\% CI 2.1-5.9; agency B: $5 \%, P=.009$, OR 2.0, 95\% CI 1.2-3.5; face-to-face: $2 \%$ ) as risk factors for 
cancer. The only risk factor that face-to-face participants were more likely to recall was having a high-fat diet (face-to-face: $5 \%$; agency A: $2 \%, P=.001$, OR $0.4,95 \%$ CI 0.3-0.7; agency B: $1 \%, P<.001$, OR $0.2,95 \%$ CI $0.1-0.3)$.

\section{Recognition of Cancer Risk Factors}

Online participants recognized more risk factors, a mean of 9 of 12 listed compared with 8 for face-to-face participants.

Participants recruited by online agencies were more likely than face-to-face participants to recognize being overweight (agency B: $74 \%, P<.001$, OR 1.4, 95\% CI 1.1-1.7; agency A: $73 \%$, $P=.004$, OR $1.3,95 \%$ CI 1.1-1.7; face-to-face: $67 \%$ ), having a family history of cancer (agency B: $77 \%, P=.02$, OR 1.3, 95\% CI 1.0-1.5; agency A: $77 \%, P<.001$, OR 1.5, 95\% CI 1.2-1.9; face-to-face: $69 \%$ ), eating too much red or processed meat (agency B: $61 \%, P<.001$, OR 1.5, 95\% CI 1.3-1.8; agency A: $58 \%, P<.001$, OR 1.5, 95\% CI 1.3-1.8; face-to-face: $52 \%$ ), and infection with human papillomavirus (HPV) as risk factors of cancer (agency A: $41 \%, P<.001$, OR 1.8, 95\% CI 1.5-2.2 agency B: $49 \%, P<.001$, OR 2.4, 95\% CI 2.0-2.9; face-to-face: $29 \%$ ). Agency B participants were more likely than face-to-face participants to recognize older age $(68 \%$ vs $60 \%, P<.001$, OR $1.4,95 \%$ CI 1.2-1.7) but less likely to recognize smoking (95\% vs $96 \%, P=.001$, OR $0.4,95 \%$ CI $0.2-0.7)$ as risk factors of cancer (Table 4).

Table 4. Percentage of participants from each sample that recognized each risk factor for cancer $(\mathrm{N}=4075)$.

\begin{tabular}{|c|c|c|c|c|c|}
\hline \multirow[t]{3}{*}{ Risk factor } & \multirow{3}{*}{$\begin{array}{l}\text { Face-to-face, } \% \\
\text { ONS }(n=819)\end{array}$} & \multicolumn{4}{|l|}{ Online } \\
\hline & & \multicolumn{2}{|c|}{ Agency A (n=1190) } & \multicolumn{2}{|c|}{ Agency B (n=2066) } \\
\hline & & Participants, $\%$ & $P$ value & Participants, $\%$ & $P$ value \\
\hline Smoking & 96.3 & 98.6 & .24 & 95.4 & .001 \\
\hline Getting sunburned & 94.0 & 94.6 & .40 & 93.7 & .42 \\
\hline $\begin{array}{l}\text { Exposure to another person's } \\
\text { smoking }\end{array}$ & 88.6 & 88.2 & .77 & 86.1 & .002 \\
\hline Drinking alcohol & 78.9 & 78.6 & .43 & 78.6 & .93 \\
\hline Having a close relative with cancer & 68.5 & 76.6 & .001 & 76.6 & .02 \\
\hline Being overweight & 66.6 & 72.8 & .004 & 74.1 & .001 \\
\hline Being older & 60.1 & 57.1 & .16 & 67.8 & .001 \\
\hline $\begin{array}{l}\text { Not eating many fruits and vegeta- } \\
\text { bles }\end{array}$ & 52.8 & 53.3 & .95 & 53.6 & .13 \\
\hline Not eating enough fiber & 52.6 & 46.4 & .10 & 49.1 & .37 \\
\hline $\begin{array}{l}\text { Eating too much red or processed } \\
\text { meat }\end{array}$ & 51.5 & 57.9 & .001 & 61.0 & .001 \\
\hline Not doing much physical activity & 49.7 & 56.1 & .002 & 55.1 & .001 \\
\hline $\begin{array}{l}\text { Infection with HPV (human papil- } \\
\text { lomavirus) }\end{array}$ & 29.2 & 41.3 & .001 & 48.9 & .001 \\
\hline
\end{tabular}

\section{Barriers to Seeing a General Practitioner}

Online survey participants were significantly more likely to endorse 8 of 14 barriers to seeing a GP than face-to-face participants. The most frequently endorsed barrier for face-to-face and agency B participants was "I find it difficult to get an appointment at a convenient time"; for agency A participants, it was "I don't like having to talk to the GP receptionist." Agency B participants were more likely than face-to-face participants to endorse an additional barrier "my doctor is difficult to talk to" $(P=.001$, OR $1.6,95 \%$ CI 1.2-2.1). Figure 2 shows the percentage of participants that endorsed barriers to going to the doctor. 
Figure 2. Percentage of participants that endorsed barriers to going to the doctor.

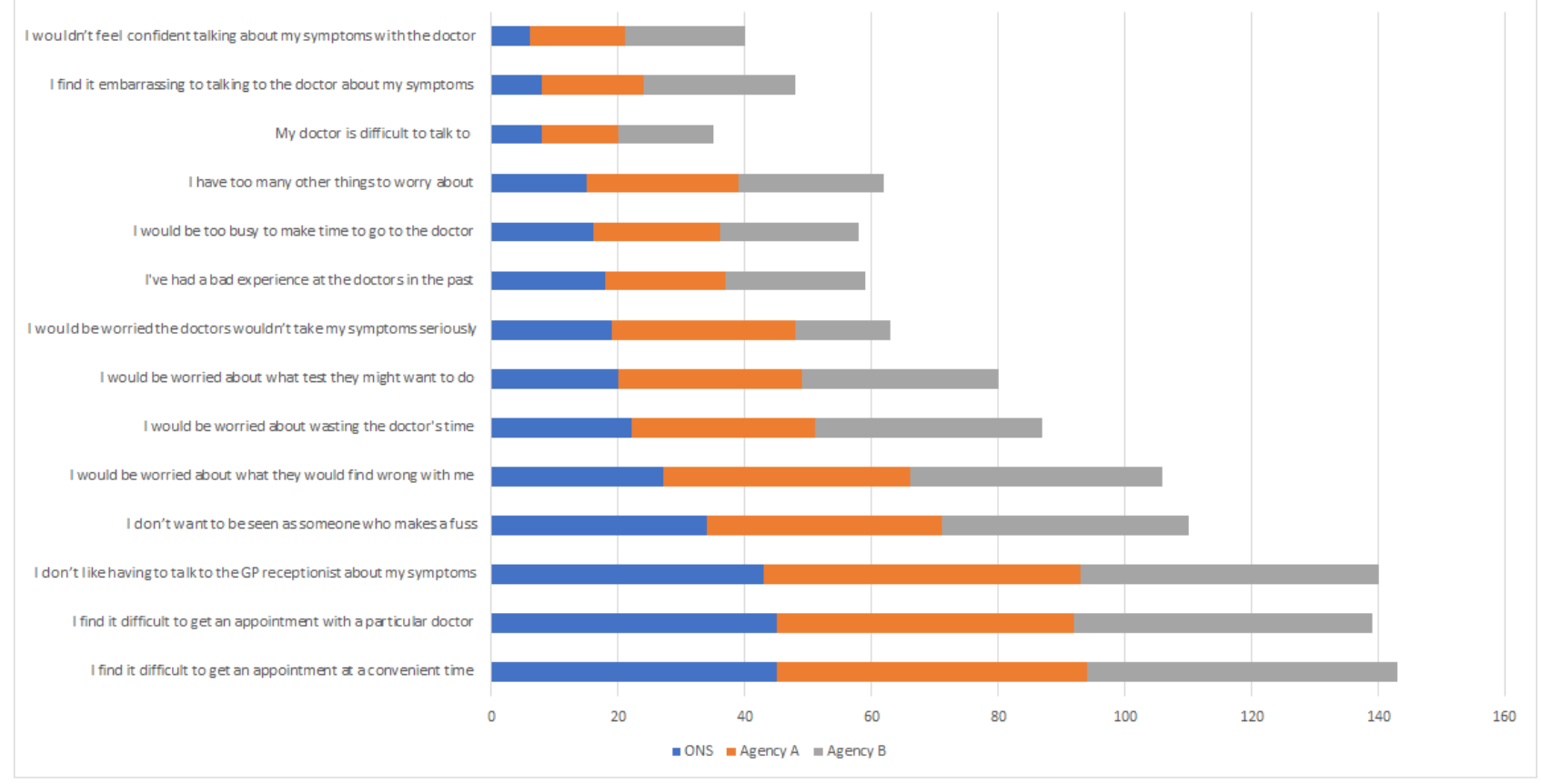

\section{Interactions Between Outcomes and Demographic Variables.}

Recall of bleeding or blood loss, cough, and difficulty swallowing showed significant interactions between sex and survey provider. For participants living in Scotland, those recruited by agency $\mathrm{B}$ were significantly less likely to recall bleeding or blood loss as a sign of cancer compared with those recruited by agency $\mathrm{A}(P=.04)$.

Fewer females recognized family history as a risk factor of cancer when completing face-to-face interviews than in online surveys (agency A females: $P=.006$; agency B females: $P<.001$ ). Significantly fewer males recognized not doing enough physical exercise as a risk factor of cancer in the agency B survey compared with agency A $(P=.02)$.

\section{Discussion}

\section{Analysis}

This analysis explored the viability of moving from face-to-face to online data collection for the Cancer Research UK's CAM.

\section{Principal Results}

Comparisons of data collected using face-to-face interviews and online surveys revealed minor differences between samples. Both methods provided broadly representative samples of the UK population with slight differences in awareness of signs, symptoms, and risk factors of cancer and frequency of help-seeking barriers reported, leading us to conclude that online data collection for the CAM is possible.

Recall of certain cancer signs and risk factors varied by demographic group. Recall of bleeding/blood loss, cough, and difficulty swallowing had significant interactions between sex and survey provider. Overall, recognition of risk factors was higher in the online surveys.

Recognition of risk factors varied by sex, education level, and country. Significantly fewer females recognized family history as a risk factor of cancer in the face-to-face survey compared with the online surveys. Significantly fewer males recognized not doing enough physical exercise as a risk factor of cancer in the online samples compared with the face-to-face sample. The reasons for these variations are unclear but provide avenues for further research and action.

Overall, online participants recruited by agency A were significantly more likely to recall cancer signs and risk factors compared with both agency B and face-to-face participants. This finding implies that agency A participants may be more engaged and knowledgeable than the other survey participants. Educational levels did not differ greatly among the three samples. Agency A participants may have been more engaged than other participants because they had previously taken part in a face-to-face survey, indicating that they may be a particularly motivated group.

\section{Comparison With Prior Work}

Previous research has found that levels of awareness of the HPV virus [26] and cholesterol [23] were higher among online than face-to-face or paper survey respondents. In this study, online participants recognized more risk factors than face-to-face participants, including being overweight, having a family history of cancer, eating too much red or processed meat, and infection with HPV (cholesterol was not assessed). However, only one of the online samples reported higher mean recall of risk factors compared with face-to-face participants. This particular panel, agency A, recruited participants after they had taken part in a paper survey, which may have resulted in a more engaged and knowledgeable sample. 
Survey research within student populations has suggested that online participants are more likely to answer "don't know" than those completing the same survey face-to-face [7]. Other research suggests that nonresponse to open-ended questions can be reduced through online data collection [8]. In this study, face-to-face participants were less likely than online participants to respond to recall questions around signs, symptoms, and risk factors with "don't know."

Socially desirable behaviors have been found to be less likely to be disclosed in interviews than online questionnaires [27,28]. In this study, online participants were more likely than face-to-face participants to endorse barriers to seeking help. Participants may have found it easier to endorse barriers to visiting the doctor with the context of anonymity afforded by online data collection compared with face-to-face data collection.

\section{Strengths and Limitations}

Although this study provides insights into the possibility of using online data collection for a large representative sample of the UK, there are limitations that warrant consideration. Regarding recruitment, large differences exist in the size of samples recruited online and face-to-face, highlighting the comparative ease of online recruitment. Previous research indicates that online research may not be as representative as face-to-face interviewing [29], but this is often based on the type of recruitment procedures that precede data collection. In this study, both online samples were recruited through panels; however, there may be differences in the ways that panels are recruited and incentivized, which may have affected the results. To mitigate this, each agency employed procedures to ensure their samples were as representative as possible of the Great Britain population.

For the analysis, it was not possible to calculate unique weighting variables, and we relied on those provided by agencies. The questions within each survey were identical; however, there may have been small differences in the presentation of questions within each sample.

It was necessary to limit the demographic variables studied to control the length of the survey, meaning that unobserved differences may have contributed to the differences observed.

It was not possible to compare the samples collected by each survey agency with the Great Britain population data. The Great Britain population data used were publicly available, although confidence intervals were not provided, and statistically significant comparisons were not possible.

It was not possible to access information about response rates or completion times within each sample. This information may have been useful to explore the differences among samples in more depth.

\section{Conclusions}

The relationships between sampling, sample representativeness, survey modality, and subsequent responses are complex. Although sample representativeness varied a little between samples and there are likely unobserved differences, we were encouraged to see that these variations were small overall. This information will be useful in helping us to tailor our recruitment strategy to ensure that we recruit a sample that is as representative as possible of the Great Britain population in future CAM research.

We observed larger differences when looking at responses to the awareness questions themselves, even between the two online samples, which point to the fact that there may be differences in the sampling and running of these panels contributing to these differences.

Nevertheless, the flexibility and potential cost savings of online data collection will enable larger samples and greater variation in content at a lower cost, which will enable the CAM to explore a new and wider range of issues related to the early diagnosis, prevention, and treatment of cancer.

\section{Acknowledgments}

Many thanks to the agencies involved in the collection of data for this research. This research was funded by Cancer Research UK.

\section{Conflicts of Interest}

None declared.

\section{Multimedia Appendix 1}

Survey Incentives and Survey Weighting Methodologies. [DOCX File, 17 KB-Multimedia Appendix 1]

\section{Multimedia Appendix 2}

Number of cancer signs and risk factors recognised and recalled within each sample. [DOCX File, $19 \mathrm{~KB}-$ Multimedia Appendix 2]

\section{References}

1. World Health Organization. 2018 Sep 12. Cancer 2018 URL: https://www.who.int/news-room/fact-sheets/detail/cancer [accessed 2019-11-06] 
2. Cancer Research UK. 2018. Cancer statistics for the UK URL: https://www.cancerresearchuk.org/health-professional/ cancer-statistics-for-the-uk\#heading-One [accessed 2019-11-06]

3. Sant M, Allemani C, Santaquilani M, Knijn A, Marchesi F, Capocaccia R, EUROCARE Working Group. EUROCARE-4. Survival of cancer patients diagnosed in 1995-1999. Results and commentary. Eur J Cancer 2009 Apr;45(6):931-991. [doi: 10.1016/j.ejca.2008.11.018] [Medline: 19171476]

4. Verdecchia A, Guzzinati S, Francisci S, De Angelis R, Bray F, Allemani C, EUROCARE Working Group. Survival trends in European cancer patients diagnosed from 1988 to 1999. Eur J Cancer 2009 Apr;45(6):1042-1066. [doi: 10.1016/j.ejca.2008.11.029] [Medline: 19124239 ]

5. Maringe C, Walters S, Rachet B, Butler J, Fields T, Finan P, ICBP Module 1 Working Group. Stage at diagnosis and colorectal cancer survival in six high-income countries: a population-based study of patients diagnosed during 2000-2007. Acta Oncol 2013 Jun;52(5):919-932. [doi: 10.3109/0284186X.2013.764008] [Medline: 23581611]

6. Møller H, Sandin F, Bray F, Klint A, Linklater KM, Purushotham A, et al. Breast cancer survival in England, Norway and Sweden: a population-based comparison. Int J Cancer 2010 Dec 01;127(11):2630-2638 [FREE Full text] [doi: 10.1002/ijc.25264] [Medline: 20162669]

7. Walters S, Maringe C, Coleman MP, Peake MD, Butler J, Young N, ICBP Module 1 Working Group. Lung cancer survival and stage at diagnosis in Australia, Canada, Denmark, Norway, Sweden and the UK: a population-based study, 2004-2007. Thorax 2013 Jun;68(6):551-564. [doi: 10.1136/thoraxjnl-2012-202297] [Medline: 23399908]

8. Niksic M, Rachet B, Duffy SW, Quaresma M, Møller H, Forbes LJ. Is cancer survival associated with cancer symptom awareness and barriers to seeking medical help in England? An ecological study. Br J Cancer 2016 Sep 27;115(7):876-886 [FREE Full text] [doi: 10.1038/bjc.2016.246] [Medline: 27537388]

9. Lyratzopoulos G, Neal RD, Barbiere JM, Rubin GP, Abel GA. Variation in number of general practitioner consultations before hospital referral for cancer: findings from the 2010 National Cancer Patient Experience Survey in England. Lancet Oncol 2012 Apr;13(4):353-365. [doi: 10.1016/S1470-2045(12)70041-4] [Medline: 22365494]

10. Bomb M, Hiom S, Kumar H, Moffat J, Ormiston-Smith N, Woolf L. Saving Lives, Averting Costs. London: Cancer Research UK; 2014 Sep. URL: https://www.cancerresearchuk.org/sites/default/files/saving_lives_averting_costs.pdf

11. McPhail S, Johnson S, Greenberg D, Peake M, Rous B. Stage at diagnosis and early mortality from cancer in England. $\mathrm{Br}$ J Cancer 2015 Mar 3;112(S1):S108-S115. [doi: 10.1038/bjc.2015.49]

12. Stubbings S, Robb K, Waller J, Ramirez A, Austoker J, Macleod U, et al. Development of a measurement tool to assess public awareness of cancer. Br J Cancer 2009 Dec 3;101(S2):S13-S17. [doi: 10.1038/sj.bjc.6605385]

13. Osborne K. Cancer Research UK. 2016. Cancer Awareness Measure (CAM) key findings report; 2014 \& trends analysis (2008-2014) URL: https://www.cancerresearchuk.org/health-professional/awareness-and-prevention/ the-cancer-awareness-measures-cam [accessed 2019-11-06]

14. Niksic M, Rachet B, Warburton FG, Wardle J, Ramirez AJ, Forbes LJL. Cancer symptom awareness and barriers to symptomatic presentation in England—are we clear on cancer? Br J Cancer 2015 Jun 30;113(3):533-542. [doi: 10.1038/bjc.2015.164]

15. Robb K, Stubbings S, Ramirez A, Macleod U, Austoker J, Waller J, et al. Public awareness of cancer in Britain: a population-based survey of adults. Br J Cancer 2009 Dec 03;101 Suppl 2:S18-S23 [FREE Full text] [doi: 10.1038/sj.bjc.6605386] [Medline: 19956158$]$

16. Niksic M, Rachet B, Duffy SW, Quaresma M, Møller H, Forbes LJ. Is cancer survival associated with cancer symptom awareness and barriers to seeking medical help in England? An ecological study. Br J Cancer 2016 Aug 18;115(7):876-886. [doi: 10.1038/bjc.2016.246]

17. Brunswick N, Wardle J, Jarvis MJ. Public awareness of warning signs for cancer in Britain. Cancer Causes Control 2001 Jan;12(1):33-37. [doi: 10.1023/a:1008975416756] [Medline: 11227923]

18. Marlow L, Robb K, Simon A, Waller J, Wardle J. Awareness of cancer risk factors among ethnic minority groups in England. Public Health 2012 Aug;126(8):702-709. [doi: 10.1016/j.puhe.2012.05.005] [Medline: 22809494]

19. Office for National Statistics. 2018 Aug 07. Internet Access: Households and Individuals in Great Britain URL: https:/ /www.ons.gov.uk/peoplepopulationandcommunity/householdcharacteristics/homeinternetandsocialmediausage/bulletins/ internetaccesshouseholdsandindividuals/2018 [accessed 2018-08-07]

20. Kongsved SM, Basnov M, Holm-Christensen K, Hjollund NH. Response rate and completeness of questionnaires: a randomized study of internet versus paper-and-pencil versions. J Med Internet Res 2007 Sep 30;9(3):e25. [doi: 10.2196/jmir.9.3.e25]

21. Wright K. Researching internet-based populations: advantages and disadvantages of online survey research, online questionnaire authoring software packages, and web survey services. J Comput-Mediat Comm 2005;10(3). [doi: 10.1111/j.1083-6101.2005.tb00259.x]

22. Roster CA, Rogers RD, Albaum G, Klein D. A comparison of response characteristics from web and telephone surveys. Int J Market Res 2018 Jan 30;46(3):359-373. [doi: 10.1177/147078530404600301]

23. Duffy B, Smith K, Terhanian G, Bremer J. Comparing data from online and face-to-face surveys. Int J Market Res 2018 Jan 30;47(6):615-639. [doi: 10.1177/147078530504700602] 
24. Comley P. Innovation in online research - who needs online panels? In: MRS Research Conference - Paper 36.2003 Presented at: MRS Research Conference; 2003; London.

25. Taylor H, Krane D, Thomas RK. How does social desirability affect responses? Differences in telephone and online. 2005 Presented at: The American Association for Public Opinion Research (AAPOR) 60th Annual Conference; May 12-15, 2005; Miami, FL. [doi: 10.4135/9781412963947.n15]

26. Sherman SM, Nailer E, Minshall C, Coombes R, Cooper J, Redman CW. Awareness and knowledge of HPV and cervical cancer in female students: a survey (with a cautionary note). J Obstet Gynaecol 2016;36(1):76-80. [doi: 10.3109/01443615.2015.1041886] [Medline: 26408400]

27. Gnambs T, Kaspar K. Disclosure of sensitive behaviors across self-administered survey modes: a meta-analysis. Behav Res 2014 Nov 20;47(4):1237-1259. [doi: 10.3758/s13428-014-0533-4]

28. Trau RN, Härtel CE, Härtel GF. Reaching and hearing the invisible: organizational research on invisible stigmatized groups via web surveys. Brit J Manage 2012 Apr 19;24(4):532-541. [doi: 10.1111/j.1467-8551.2012.00826.x]

29. Szolnoki G, Hoffmann D. Online, face-to-face and telephone surveys-comparing different sampling methods in wine consumer research. Wine Econ Policy 2013 Dec;2(2):57-66. [doi: 10.1016/j.wep.2013.10.001]

\section{Abbreviations \\ CAM: Cancer Awareness Measure \\ HPV: human papillomavirus \\ NHS: National Health Service \\ ONS: Office for National Statistics}

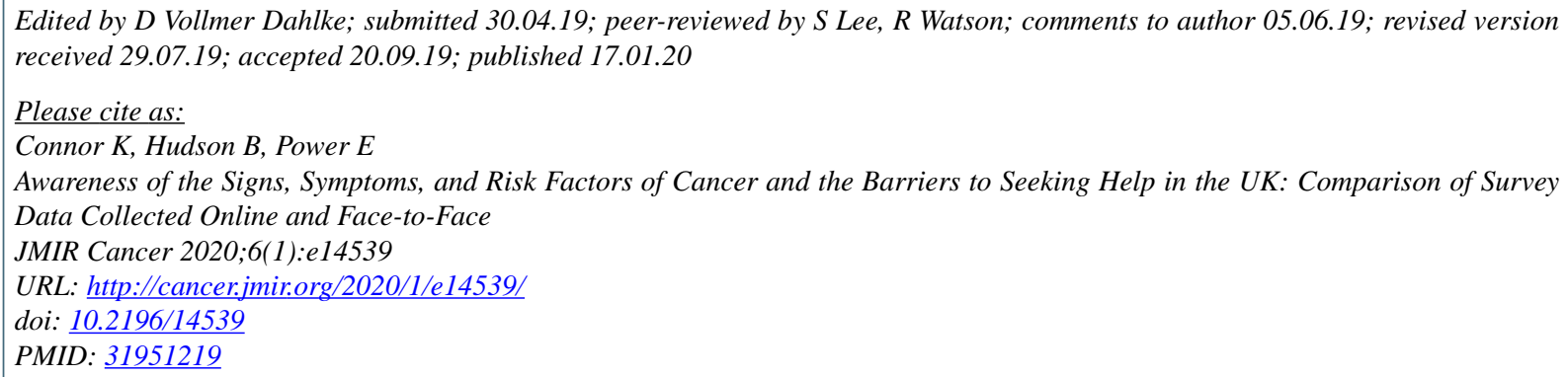

CKatie Connor, Briony Hudson, Emily Power. Originally published in JMIR Cancer (http://cancer.jmir.org), 17.01.2020. This is an open-access article distributed under the terms of the Creative Commons Attribution License (https://creativecommons.org/licenses/by/4.0/), which permits unrestricted use, distribution, and reproduction in any medium, provided the original work, first published in JMIR Cancer, is properly cited. The complete bibliographic information, a link to the original publication on http://cancer.jmir.org/, as well as this copyright and license information must be included. 